\title{
A Rare Cause of Abdominal Pain: Intestinal Angioedema
}

\author{
Tania Araujo Ferreira ${ }^{\mathrm{a}, \mathrm{c}}$, Marta Rebocho Alves ${ }^{\mathrm{a}}$, Ana Maria Pinheiro Oliveira ${ }^{\mathrm{a}}$, \\ Filipa Sofia Santos Silva ${ }^{b}$, Claudia Pereira ${ }^{a}$
}

\begin{abstract}
Angioedema with evidence of mucosal swelling is a rare condition that can be caused by angiotensin-converting enzyme inhibitors. The authors describe a case of a 28 -year-old woman medicated with lisinopril 2 months before, with abdominal pain associated with nausea, vomiting and a onetime watery stool. A small volume of ascites was found in the abdominal ultrasound and the parietal thickening of the middle ileum in the abdominal computed tomography (CT). The complementary study was negative. The symptoms stopped after drug withdrawal. The authors intend to warn to this diagnosis, which has non-specific symptoms and if not suspected, can lead to a great morbidity for patients. The authors also intend to identify various signs that can be clues for its correct diagnosis.
\end{abstract}

Keywords: Intestinal angioedema; Angiotensin-converting enzyme inhibitor; Side effects; Abdominal pain

\section{Introduction}

Angioedema with evidence of mucosal swelling is a rare condition that can occur in any part of the body. An isolated intestinal angioedema is even less common but can lead to a great morbidity [1-3]. It can have several etiologies, from hereditary to a drug reaction, especially from angiotensinconverting enzyme inhibitors (ACEIs) [1]. Its incidence is rising due to the increased use of these drugs, occurring in up to $1 \%$ of patients with angioedema [4-7]. Its diagnostic is difficult because of the non-specific symptoms (abdominal pain, nausea, vomiting or diarrhea) often related with other pathologies, such as gastroenteritis and inflammatory bowel

Manuscript submitted January 13, 2021, accepted January 21, 2021

Published online February 8, 2021

${ }^{a}$ Internal Medicine Department, Porto University Hospital Center (Centro Hospitalar Universitario do Porto), Porto, Portugal

bNephrology Department, Porto University Hospital Center (Centro Hospitalar Universitario do Porto), Porto, Portugal

${ }^{\mathrm{c} C}$ Corresponding Author: Tania Araujo Ferreira, Internal Medicine Department, Porto University Hospital Center (Centro Hospitalar Universitario do Porto), Largo Prof Abel Salazar, 4099-001 Porto, Portugal.

Email: araujoferreira.tania@gmail.com

doi: https://doi.org/10.14740/jmc3651 disease (IBD) [4].

\section{Case Report}

The patient was a 28 -year-old woman, diagnosed with arterial hypertension 2 months before and medicated with lisinopril and an oral contraceptive. She was admitted to the emergency room with a generalized and intense (8/10) abdominal pain associated with nausea, vomiting and a single episode of watery stool. The patient did not report any fever, labial edema, dyspnea or similar.

In the objective examination, she was hypertensive (blood pressure of 200/140 $\mathrm{mm} \mathrm{Hg}$ ) without evidence of cardiac dysfunction or fever and her abdomen was distended and painful to superficial and deep palpation. No other changes were found, namely in the oropharynx and in the cardiopulmonary, anorectal and neurological systems.

The clinical analysis revealed leukocytosis $(20,590 / \mu \mathrm{L})$ with neutrophils predominance and negative C-reactive protein. There were no other significant abnormalities. The patient was also submitted to an abdominal ultrasound which revealed a small volume of ascites scattered throughout the four quadrants. This was confirmed by an abdominal computed tomography $(\mathrm{CT})$ scan that also showed a parietal thickening of a 20 $\mathrm{cm}$ segment in the middle ileum.

According to the initial findings, the main hypothesis was IBD with subocclusive presentation associated with a hypertensive urgency. Therefore, the patient was admitted to an intermediate care unit and treated with a beta-blocker and a calcium channel blocker. At the same time, she stopped taking the ACEI. Given the condition severity and the clinical suspicion, the patient was medicated with antibiotics and corticoids empirically. This unsuccessful strategy was suspended $48 \mathrm{~h}$ later, since there was no support for maintaining it: the microbiological and autoimmune studies came back all negative. Thus, other diagnoses were considered, such as intestinal angioedema caused by ACEIs. This hypothesis was also supported by the clinical evolution of the case: fast clinical recovery, continuous apyrexia, no inflammatory syndrome associated, quick resolution of the imagiological findings and negative results for the microbiological studies, serologies, autoimmune parameters and hereditary angioedema.

The patient was discharged and has been followed as an outpatient, asymptomatic and without a record of new episodes. She has normal blood pressure, does not take ACEI anymore and the study pending secondary causes for hypertension came back negative. 


\section{Discussion}

Intestinal angioedema is a rare condition that is very difficult to diagnose. It occurs essentially as a result of ACEIs taking. Out of these, the most common one is lisinopril [4, 8]. ACEs can lead to bradykinin accumulation due to its lack of degradation, causing vasodilation and vascular permeability that in turn result in mucosal edema $[2,5,6]$.

This event can occur any time during ACEI pharmacotherapy, but most of them occur in the first year of use, ranging from days to several years $[5,6,8]$. The condition is more common in women and black people and manifests with more frequency in the jejunum, followed by the ileum [6, 9-12].

Symptoms are non-specific and not taken into account sometimes, especially when isolated, with no other mucous membranes involved, leading to underdiagnoses [13]. The most referred symptoms are abdominal pain, vomiting and diarrhea (mostly watery) $[6,8-10]$ and the laboratory results are usually normal [6]. Concerning imagiology, the most common finding is the parietal thickening of part of the intestine, sometimes with ascites $[5,6]$. This clinical, laboratory and imagiology presentation is similar in many other conditions, such as infectious diseases, inflammations and even hereditary angioedema. Therefore, clinical suspicion must be at the highest level, where findings are taken into account for coming back negative. In this case, other pathologies were excluded due to the absence of fever and inflammatory syndrome and due to the fast clinical resolution after drug withdrawal with no record of reoccurrence. The inexistence of other imagiology findings such as fistulous paths, abdominal fat densification and adenopathies, which could indicate other pathologies [5], also contributed to the final diagnosis.

The treatment involves drug withdrawing and supporting measures, with symptom resolution within $48 \mathrm{~h}$ in most cases $[5,6]$.

Therefore, the authors describe the case of a young woman recently medicated with lisinopril, who had clinical and imagiology findings compatible with intestinal angioedema caused by that drug, with no other mucosae affected. Intestinal mucous edema is even rarer when relating to angioedema caused by ACEI. This finding was more suggestive of an inflammatory/infectious process. In this setting, the ascites found were a discriminating factor giving its infrequency in IBD. Finally, the symptoms disappeared after drug withdrawal, with no reoccurrence and with no other condition being the probable cause for her symptoms.

The authors want to raise awareness about this rare condition that is caused by ACEIs, very commonly used in the daily practice. The associated symptoms can cause great morbidity, with several admissions to the emergency department and consequently unnecessary exams. The authors also intend to warn that some of the findings can be discriminatory, such as ascites, diverging from IBD and leaning towards the diagnosis of intestinal angioedema caused by ACEIs.

\section{Acknowledgments}

None to declare.

\section{Financial Disclosure}

None to declare.

\section{Conflict of Interest}

None to declare.

\section{Informed Consent}

Not applicable.

\section{Author Contributions}

Tania Ferreira performed the diagnostic investigation, collected data, wrote the article, submitted and revised it. Marta Alves and Claudia Pereira performed the diagnostic investigation, collected data and revised the article. Ana Oliveira and Filipa Silva performed the diagnostic investigation and revised the article.

\section{Data Availability}

Any inquiries regarding supporting data availability of this study should be directed to the corresponding author.

\section{References}

1. Belkhouribchia J, Backaert T, Neyrinck S. Isolated intestinal angioedema in the emergency department. J Emerg Med. 2016;50(4):660-662.

2. Locascio EJ, Mahler SA, Arnold TC. Intestinal angioedema misdiagnosed as recurrent episodes of gastroenteritis. West J Emerg Med. 2010;11(4):391-394.

3. Cicardi M, Bergamaschini L, Marasini B, Boccassini G, Tucci A, Agostoni A. Hereditary angioedema: an appraisal of 104 cases. Am J Med Sci. 1982;284(1):2-9.

4. Palmquist S, Mathews B. Isolated intestinal type angioedema due to ACE-inhibitor therapy. Clin Case Rep. 2017;5(5):707-710.

5. Vallabh H, Hahn B, Bryan C, Hogg J, Kupec JT. Small bowel angioedema from angiotensin-converting enzyme: Changes on computed tomography. Radiol Case Rep. 2018;13(1):55-57.

6. Frutuoso B, Esteves J, Silva M, Gil P, Carneiro AC, Vale $\mathrm{S}$. Visceral angioedema induced by angiotensin converting enzyme inhibitor: case report. GE Port J Gastroenterol. 2016;23(3):166-169.

7. Campbell T, Peckler B, Hackstadt RD, Payor A. ACE inhibitor-induced angioedema of the bowel. Case Rep Med. 2010;2010:690695.

8. Bruetman JE, Montes Ongania A, Finn BC, Young P. [Isolated intestinal angioedema induced by enalapril]. Medicina (B Aires). 2018;78(1):41-43. 
9. Scheirey CD, Scholz FJ, Shortsleeve MJ, Katz DS. Angiotensin-converting enzyme inhibitor-induced smallbowel angioedema: clinical and imaging findings in 20 patients. AJR Am J Roentgenol. 2011;197(2):393-398.

10. Korniyenko A, Alviar CL, Cordova JP, Messerli FH. Visceral angioedema due to angiotensin-converting enzyme inhibitor therapy. Cleve Clin J Med. 2011;78(5):297-304.

11. Oudit G, Girgrah N, Allard J. ACE inhibitor-induced angioedema of the intestine: Case report, incidence, patho- physiology, diagnosis and management. Can J Gastroenterol. 2001;15(12):827-832.

12. Benson BC, Smith C, Laczek JT. Angiotensin converting enzyme inhibitor-induced gastrointestinal angioedema: a case series and literature review. J Clin Gastroenterol. 2013;47(10):844-849.

13. Voore N, Stravino V. Isolated small bowel angiooedema due to ACE inhibitor therapy. BMJ Case Rep. 2015;2015:bcr2015212623. 